\title{
LA OBLIGACIÓN DE DAR AVISO OPORTUNO DEL SINIESTRO A LA ASEGURADORA EN EL SEGURO DE RESPONSABILIDAD CIVIL
}

\section{THE DUTY OF REPORTING THE LOSS ON TIME TO THE INSURER IN LIABILITY INSURANCE}

\author{
ANDRÉS ORIÓN ÁLVAREZ PÉREZ* \\ Fecha de recepción: 3 de abril de 2019 \\ Fecha de aceptación 30 junio de 2019 \\ Disponible en línea: 30 de Julio de 2019
}

Para citar este artículo/To cite this article

Álvarez Pérez, Andrés Orión, La obligación de dar aviso oportuno del siniestro a la aseguradora en el seguro de responsabilidad civil, 50 Rev.Ibero-Latinoam.Seguros, 15-36 (2019). https://doi.org/10.11144/Javeriana.ris50.odao

doi:10.11144/Javeriana.ris50.odao

* Abogado Universidad de Medellín, Especialista en Derecho Público, Universidad Externado de Colombia, Especialista en Derecho de Seguros, Pontificia Universidad Javeriana, Magister en Derecho de Daños, Universidad de Girona, España, curso de Especialización en Derecho de Seguros, Universidad de Salamanca, España, Director de la Revista Responsabilidad Civil y del Estado, Cofundador y miembro de Junta Directiva del Instituto Colombiano de Responsabilidad Civil y del Estado, IARCE, miembro de la Asociación Colombiana de Derecho de Seguros, ACOLDESE. https:// orcid.org/0000-0003-4528-7925. Contacto: aorion@aoa.com.co 


\section{RESUMEN}

Establecen los diferentes ordenamientos jurídicos objeto de análisis comparativo, en términos generales, la obligación del asegurado de dar aviso oportuno a la aseguradora sobre la ocurrencia del siniestro. A renglón seguido, se establece la forma en que la Compañía puede deducir los perjuicios que se le causen por el incumplimiento de dicha obligación, carga o deber, en cada caso particular.

Se pretende entonces hacer un análisis crítico de la norma, profundizando más en el caso Colombiano, pero trayendo la normatividad de países como España, México, Bolivia, Argentina, y Brasil, para hacer una propuesta final, dadas las verdaderas implicaciones actuariales, presupuestales, de cálculo de prima, de asunción del riesgo, y demás circunstancias que analizaremos al respecto, para que la norma en realidad tenga fuerza coercitiva y vinculante, y objetivamente genere la atención y el cumplimiento en cabeza de los asegurados.

Palabras clave: Aviso de siniestro; cálculo de la prima; incremento de la siniestralidad; perjuicios causados a la aseguradora; renovación del contrato. 


\begin{abstract}
Some legal systems, specifically the ones that are subject of matter in this paper, have incorporated an obligation of prompt notice of the loss to the insurance company. That same rule states that insurance company may only deduct from the settlement an amount that correspond to the damages that late notification cause them.

This paper intends to be a critical analysis about the mentioned rule, mainly focused in the Colombian case, but also taking into account the matter in other countries, like Spain, Mexico, Bolivia, Argentina and Brazil. With this approach we will analyze different elements such as the actuarial and budget implications, the premium calculation, policy underwriting, efforts that are essentially aimed at giving the rule obligatory force and binding power, so it accomplishes its purposes.
\end{abstract}

Keywords: Contract renewal; damages; increase of the loss rates; insurance company; notification of loss; premium calculation.

\title{
SUMARIO
}

INTRODUCCIÓN. 1. LEGISLACIÓN SOBRE LA MATERIA. 1.1. Colombia. 1.2. España. 1.3. México. 1.4. Argentina. 1.5. Bolivia. 1.6. Brasil. 2. LOS PERJUICIOS A FAVOR DE LA ASEGURADORA Y LA DIFICULTAD PRÁCTICA EN LA APLICACIÓN DE LA NORMA. 2.1. Determinación del valor de los perjuicios a favor del asegurador. 2.2. Seguros obligatorios de responsabilidad civil en Colombia. 3. ALGUNAS PROPUESTAS O EVENTUALES SOLUCIONES. 3.1. Garantía. 3.2. Deducibles diferenciales. . BIBLIOGRAFÍA. JURISPRUDENCIA 



\section{INTRODUCCIÓN}

Se pretende con el presente trabajo, hacer un análisis sobre la figura consagrada en el contrato de seguro, como la obligación, deber o carga - cada régimen normativo podrá darle una u otro nivel de exigencia - del asegurado de dar aviso oportuno a la aseguradora, sobre la ocurrencia del siniestro, y aunque se trata de una obligación transversal al contrato de seguro en general, y por tanto a cualquier forma de aseguramiento o producto, se hará mayor referencia al seguro de responsabilidad civil.

Así las cosas, sin aspirar a hacer un gran estudio de derecho comparado, lo cual de suyo sonaría muy pretensioso, si se hará mención a la reglamentación legal de esta figura en España, y en algunos países de Latinoamérica, entre ellos, Argentina, México, Brasil, Bolivia y desde luego nuestro país, Colombia.

Ello llevará además a abordar temas afines y que de alguna manera sustentan la idea del equilibrio contractual, como la buena fe, el deber de evitar la extensión y propagación del siniestro, el deber de mitigar el daño, y en fin, instituciones comunes que buscan de alguna manera conservar los derechos de las partes en el contrato, en algún grado de igualdad o equilibrio, en tanto, la omisión de este deber a cargo del asegurado, sin duda genera serias desventajas para la aseguradora, quien por la omisión del aviso oportuno sobre la ocurrencia del siniestro, correrá con incrementos innecesarios, y sobre todo injustificados en el valor de la pérdida, ausencia de control del siniestro, desviaciones marcadas de la siniestralidad, en fin, sorpresas indeseadas, en la medida en que avanza un detrimento patrimonial asegurado bajo el amparo de responsabilidad civil, sin su conocimiento, control, dirección, administración, y si se quiere, atención temprana, eficiente y oportuna, con sus desfavorables resultados.

\section{LEGISLACIÓN SOBRE LA MATERIA}

Se hará un repaso por los referidos países, citando textualmente la norma y en algunos casos doctrina o jurisprudencia, con el claro propósito de poner en 
contexto al lector sobre la reglamentación positiva en cada ordenamiento, lo que nos conducirá en dicho análisis comparativo, a destacar la reglamentación que en forma más asertiva tenga reglamentado el tema, en beneficio de un derecho que ostenta la aseguradora, y cuyo incumplimiento le genera serios perjuicios, no sólo en el incremento desbordado e incontrolado de la siniestralidad, sino en el buen manejo y además acertado cálculo de las reservas, con las implicaciones financieras, presupuestales y sancionatorias que ello conlleva. Veamos:

\subsection{Colombia}

CÓDIGO DE COMERCIO, DECRETO LEY 410 DE 1971

Artículo 1074. Obligación de evitar la extensión y propagación del siniestro. Ocurrido el siniestro, el asegurado estará obligado a evitar su extensión y propagación, y a proveer al salvamento de las cosas aseguradas.

El asegurador se hará cargo, dentro de las normas que regulan el importe de la indemnización, de los gastos razonables en que incurra el asegurado en cumplimiento de tales obligaciones.

Artículo 1075. Aviso de la ocurrencia del siniestro. El asegurado o el beneficiario estarán obligados a dar noticia al asegurador de la ocurrencia del siniestro, dentro de los tres días siguientes a la fecha en que lo hayan conocido o debido conocer. Este término podrá ampliarse, mas no reducirse por las partes. (Negrillas y subrayas fuera de texto).

El asegurador no podrá alegar el retardo o la omisión sí, dentro del mismo plazo, interviene en las operaciones de salvamento o de comprobación del siniestro.

Artículo 1078. Reducción de la indemnización por incumplimiento. Si el asegurado o el beneficiario incumplieren las obligaciones que les corresponden en caso de siniestro, el asegurador sólo podrá deducir de la indemnización el valor de los perjuicios que le cause dicho incumplimiento.

La mala fe del asegurado o del beneficiario en la reclamación o comprobación del derecho al pago de determinado siniestro, causará la 
pérdida de tal derecho. (Subraya fuera de texto).

Puntualmente la norma que establece la obligación de dar aviso al asegurador de la ocurrencia del siniestro es el artículo 1075 de nuestro ordenamiento mercantil, pero se citan adicionalmente los artículos 1074 y 1078; el primero, porque de alguna manera dentro la obligación de evitar la extensión y propagación del siniestro se incluye entre otras, la de dar aviso oportuno del mismo, y el segundo, porque se establece el mecanismo para indemnizar los perjuicios al asegurador que no fue informado oportunamente de la ocurrencia del siniestro. Sobre el mecanismo y aplicación de la indemnización a favor de la aseguradora, volveremos más adelante, aunque lo anticipamos desde ya, en nuestro sentir se trata de una reglamentación poco clara, además de confusa e inaplicable en la práctica.

\subsection{España}

En España, es la Ley 50/1980, de 8 de octubre, la que regula el Contrato de Seguro, y específicamente el tema objeto de análisis, lo encontramos en el artículo 16, veamos:

Artículo 16. El tomador del seguro o el asegurado o el beneficiario deberán comunicar al asegurador el acaecimiento del siniestro dentro del plazo máximo de siete días de haberlo conocido, salvo que se haya fijado en la póliza un plazo más amplio. En caso de incumplimiento, el asegurador podrá reclamar los daños y perjuicios causados por la falta de declaración.

Este efecto no se producirá si se prueba que el asegurador ha tenido conocimiento del siniestro por otro medio. El tomador del seguro o el asegurado deberá, además, dar al asegurador toda clase de informaciones sobre las circunstancias y consecuencias del siniestro. En caso de violación de este deber, la pérdida del derecho a la indemnización sólo se producirá en el supuesto de que hubiese concurrido dolo o culpa grave. (Subraya fuera de texto). 


\subsection{México}

LEY SOBRE EL CONTRATO DE SEGURO: agosto 30 de 1935

Artículo 66. Tan pronto como el asegurado o el beneficiario en su caso, tengan conocimiento de la realización del siniestro y del derecho constituido a su favor por el contrato de seguro, deberán ponerlo en conocimiento de la empresa aseguradora.

Salvo disposición en contrario de la presente ley, el asegurado o el beneficiario gozarán de un plazo máximo de cinco días para el aviso que deberá ser por escrito si en el contrato no se estipula otra cosa.

Artículo 67.- Cuando el asegurado o el beneficiario no cumplan con la obligación que les impone el artículo anterior, la empresa aseguradora podrá reducir la prestación debida hasta la suma que habría importado si el aviso se hubiere dado oportunamente. (Subraya fuera de texto).

Artículo 68.- La empresa quedará desligada de todas las obligaciones del contrato, si el asegurado o el beneficiario omiten el aviso inmediato con la intención de impedir que se comprueben oportunamente las circunstancias del siniestro.

Existe igualmente el deber de poner en conocimiento de la aseguradora la realización del siniestro, en este caso en un plazo de 5 días. Del mismo modo, pero con expresiones diferentes, se faculta a la Compañía de seguros a "reducir la prestación debida hasta la suma que habría importado si el aviso se hubiere dado oportunamente", y finalmente se establece la sanción por la mala fe en la reclamación, que como en Colombia, será la pérdida del derecho, y aunque la norma Mexicana no referencia exactamente la mala fe o el dolo, si habla de la "intención de impedir que se comprueben oportunamente las circunstancias del siniestro".

\subsection{Argentina}

\section{LEY DE SEGUROS}

En Argentina tenemos la Ley de Seguros No. 17.418 de agosto 30 de 1967, pero sin duda "tocada", si se permite el término, esto es, influenciada por el nuevo Código Civil y de Comercio proferido en este país recientemente, 
contenido en la Ley 27.077 de octubre $1^{\circ}$ de 2014, el cual entró en vigencia el $1^{\circ}$ de agosto de 2015, así como por la Ley de Defensa de Consumidores y Usuarios.

Artículo 46. Denuncia del siniestro.

El tomador, o derechohabiente en su caso, comunicará al asegurador el acaecimiento del siniestro dentro de los tres días de conocerlo. El asegurador no podrá alegar el retardo o la omisión si interviene en el mismo plazo en las operaciones de salvamento o de comprobación del siniestro o del daño.

Informaciones.

Además, el asegurado está obligado a suministrar al asegurador, a su pedido, la información necesaria para verificar el siniestro o la extensión de la prestación a su cargo y a permitirle las indagaciones necesarias a tal fin.

Art. 47. Mora. Sanción. El asegurado pierde el derecho a ser indemnizado, en el supuesto de incumplimiento de la carga prevista en el párrafo $1^{\circ}$ del artículo 46, salvo que acredite caso fortuito, fuerza mayor o imposibilidad de hecho sin culpa o negligencia. (Subraya fuera de texto).

Art. 48. Incumplimiento malicioso del artículo 46, párrafo $2^{\circ}$. El asegurado pierde el derecho a ser indemnizado si deja de cumplir maliciosamente las cargas previstas en el párrafo $2^{\circ}$ del artículo 46 , o exagera fraudulentamente los daños o emplea pruebas falsas para acreditar los daños.

Es sin duda la norma que más protege al asegurador frente al incumplimiento del asegurado de su obligación de dar aviso del siniestro en forma oportuna, pues consagra una sanción contundente, y por lo menos exigible con mayor claridad, al establecer como consecuencia la pérdida del derecho del asegurado a ser indemnizado, sin exigir para ello la comprobación de culpa grave o dolo, como en Colombia, México o España. 


\title{
1.5. Bolivia
}

CÓDIGO DE COMERCIO, Decreto Ley No. 14.379 de febrero 25 de 1977

\begin{abstract}
Art. 1028.- Aviso del siniestro. El asegurado o beneficiario, tan pronto y a más tardar dentro de los tres días de tener conocimiento del siniestro, deben comunicar tal hecho al asegurador, salvo fuerza mayor o impedimento justificado. Este plazo no se aplica si se señala otro diferente en seguros específicos de este Título. Los términos señalados pueden ampliarse mediante cláusula del contrato pero no reducirse. No se puede invocar retardación u omisión del aviso cuando el asegurador o sus agentes, dentro del plazo indicado, intervengan en el salvamento o comprobación del siniestro al tener conocimiento del mismo por cualquier medio.
\end{abstract}

\begin{abstract}
Art. 1030.- Omisión del aviso. El asegurador puede liberarse de sus obligaciones cuando el asegurado o beneficiario, según el caso, omitan dar el aviso dentro del plazo del artículo 1028 con el fin de impedir la comprobación oportuna de las circunstancias del siniestro o el de la magnitud de los daños. (Subrayas fuera de texto).
\end{abstract}

Esta última parte de la norma, hace referencia de alguna manera a la mala fe, el dolo o la culpa grave del asegurado, como ocurre en los países ya citados, Colombia, España y México, es decir, condiciona la pérdida del derecho a la indemnización sólo a la conducta dolosa o gravemente culposa del asegurado, a diferencia de Argentina.

\subsection{Brasil}

CÓDIGO CIVIL, LEY 10.406 de enero 10 de 2002

En Brasil, la reglamentación del contrato de seguro, a diferencia de los demás países analizados, está contenido en el Código Civil, en los artículos 757 y siguientes, y específicamente el tema objeto de estudio, se regula en el artículo 771, veamos: 
Art. 771. Bajo pena de perder el derecho a la indemnización, el asegurado participará el siniestro al asegurador, tan pronto como lo sepa, y tomará las providencias inmediatas para aliviarle las consecuencias.

Párrafo único. Corren a la cuenta del asegurador, hasta el límite fijado en el contrato, los gastos de salvamento consecuente al siniestro.

Aunque no se profundiza mucho al respecto, si establece la "pena de perder el derecho a la indemnización", sin condicionarlo a la culpa grave o al dolo, como lo hemos visto en otras legislaciones.

\begin{tabular}{|l|l|l|}
\hline \multicolumn{1}{|c|}{ PAIS } & \multicolumn{1}{c|}{ NORMA } & \multicolumn{1}{c|}{ FECHA DE LA NORMA } \\
\hline Colombia & Código de Comercio & Decreto 410 de 1971 \\
\hline Esapña & Ley de contrato de seguro & Ley 50 de 1980 \\
\hline México & Ley de contrato de seguro & Agosto de 1935 \\
\hline Argentina & Ley de Seguros & Ley 10.406 de 1967 \\
\hline Bolivia & Código de Comercio & Decreto Ley 14.379 de 1977 \\
\hline Brasil & Código Civil & Ley 10.406 de 2002 \\
\hline
\end{tabular}

Aunque no es objeto de estudio y análisis, llama la atención la antigüedad de las legislaciones en materia de seguros, pues si notamos, por lo menos en los países objeto de comparación, con excepción de Brasil (2002), tenemos normas desde 1935 hasta 1980, lo que podría motivar la conducta de ir repensando muchos temas, ajustando y actualizando la normatividad, de cara a las nuevas tecnologías, a las diversas formas de comunicaciones, a la forma y clases de suscripción, a las nuevas corrientes Europeas y mundiales en materia del derecho de consumo, a los nuevos ordenamientos constitucionales, al deber calificado de información, en ambos sentidos, al desarrollo del principio de la buena fe y de los remedios contractuales, en fin, a grandes avances que ha tenido la humanidad en estos últimos 40 o 50 años, que aunque incorporados en otras normas que alimentan de alguna manera el derecho de seguros, pensamos que podría ser útil y pertinente, actualizar, armonizar y ajustar la reglamentación en varios países, de tan importante contrato mercantil. 


\section{LOS PERJUICIOS A FAVOR DE LA ASEGURADORA Y LA DIFICULTAD PRÁCTICA EN LA APLICACIÓN DE LA NORMA}

El citado artículo 1075, norma que establece el deber de dar aviso sobre la ocurrencia de siniestro, es de carácter imperativo, en las voces del artículo 1162 del estatuto mercantil Colombiano, lo que implica que las partes no pueden disponer en contrario, no pueden pactar diferente, contractualmente no pueden desaparecer el deber o la obligación, es pues una norma inmodificable por la convención, el acuerdo o el contrato, pero aunque protegida por el ordenamiento jurídico, consideramos que le faltan "dientes", poder coercitivo, un mecanismo más claro y contundente para el cobro de los perjuicios causados por la conducta descuidada, desinteresada y desidiosa del asegurado, al omitir dar aviso de la ocurrencia del siniestro, pues la norma solo determina que "el asegurador sólo podrá deducir de la indemnización el valor de los perjuicios que le cause dicho incumplimiento"; claro homenaje a la bandera, impracticable la norma, o piénsese como operaría en la siguiente hipótesis frente al amparo de responsabilidad civil: el asegurador calcula objetiva, seria y fundadamente unos perjuicios, los podrá deducir del valor de la indemnización debida al tercero - víctima?. No, y no porque no estamos en frente de la figura de la compensación, como medio para extinguir las obligaciones, regulada en los artículos $1714^{1}$ y siguientes del Código Civil Colombiano. En consecuencia la compañía de seguros deberá tramitar una reclamación judicial o extrajudicial dirigida al asegurado, y mientras tanto que, ¿se desatiende la obligación debida al tercero en virtud de la responsabilidad civil amparada? Enrarecido panorama, o dicho de otra manera, si se quiere más gráfica, pero ilustrativa: Señor víctima, beneficiario de las prestaciones derivadas del amparo de responsabilidad civil, le informo que deberá esperarse un tiempo - además considerable - mientras resuelvo con mi asegurado, su victimario, un tema relativo a mis perjuicios como asegurador por no haber recibido la noticia de la ocurrencia del sinestro a tiempo, y lo que resulte de este debate, se lo abono para cubrir

1 Código Civil Colombiano Art. 1714,: "Cuando dos personas son deudoras una de otra, se opera entre ellas una compensación que extingue ambas deudas, del modo y en los casos que van a explicarse"

Art. 1715 Ibídem: "La compensación se opera por el sólo ministerio de la ley y aun sin conocimiento de los deudores; y ambas deudas se extinguen recíprocamente hasta la concurrencia de sus valores, desde el momento que una y otra reúnan las calidades siguientes:

Que sean ambas de dinero o de cosas fungibles o indeterminadas, de igual género y calidad.

Que ambas deudas sean líquidas

Que ambas sean actualmente exigibles 
parcialmente sus perjuicios, en el entendido de que el saldo podrá cobrárselo a mi asegurado, a quien le desconté del monto a su favor, unos perjuicios que por su conducta descuidada me adeuda en virtud del artículo 1078 ibídem. Impensable! Ofrezco disculpas al lector por lo crudo del anterior planteamiento, pero en ocasiones, por apoyarnos en grandes dogmas y estilizadas redacciones doctrinarias, no expresamos con claridad el centro del debate, sacrificando el fondo por la forma; la norma hay que analizarla con claridad y pensar si en realidad esa hipótesis que plantea el legislador es aplicable en la práctica, si resuelve un problema de la sociedad, por demás rutinario, o si por el contrario, no se traduce en más que una hipótesis inaplicable, como pensamos que es en el caso Colombiano.

\subsection{Determinación del valor de los perjuicios a favor del asegurador}

Así las cosas, tenemos claro que si no opera la figura de la compensación, como forma de extinguir las obligaciones, en tanto ambas obligaciones no son líquidas, ni mucho menos en ese momento exigibles, deberá la aseguradora acudir al trámite judicial o extrajudicial tendiente a acreditar "el valor de los perjuicios que le cause dicho incumplimiento", cita textual y parcial de la norma objeto de análisis, para que, - es mi postura personal - luego acuda ante su asegurado, independientemente del trámite de la reclamación del tercero que pretende afectar el amparo de responsabilidad civil, a cobrar dichos perjuicios.

Al respecto, sobre la forma en que la aseguradora podrá ejercer su acción para el reconocimiento y pago de los perjuicios, es pertinente citar al tratadista, profesor y abogado litigante en Colombia, Hernán Fabio López Blanco:2 "Ciertamente, en el artículo 1078 del Código de Comercio, no se consagra de manera directa un caso de compensación, porque este modo de extinción de las obligaciones para generar sus efectos necesita que se den los requisitos establecidos en el artículo 1715 del Código Civil, es decir, que se trate de obligaciones en dinero, que ambas deudas sean líquidas y actualmente exigibles y tales condiciones, excepto la primera, no se cumplen en el caso ya que la empresa aseguradora no es la llamada a tasar los perjuicios.

2 López Blanco, H. F. “Comentarios al contrato de seguro”, págs. 186 - 187. Dupré Editores, Quinta Edición, Bogotá, 2010, Colombia. 
Es por eso que, salvo el caso de acuerdo expreso entre las partes sobre el punto, no puede la aseguradora, sin previo adelantamiento de un proceso ordinario en contra del asegurado o beneficiario, en el cual se declare, en sentencia ejecutoriada, el monto de los perjuicios, hacer efectiva la sanción que como consecuencia del incumplimiento en el aviso del siniestro o, en general, de las obligaciones con ocasión de un siniestro, pueda ser aplicable en su favor.

Piénsese que el asegurado o beneficiario acredita cabalmente la existencia del siniestro y su cuantía, todo lo cual acepto la empresa; no existe base legal alguna para que la aseguradora pueda deducir, por la derecha (compensación), una cantidad incluso hasta el monto de la indemnización, pretextando la existencia de perjuicios que ella unilateralmente no pueda tasar, pues la norma la faculta para deducir los perjuicios causados y comprobados, no para señalarlos. A lo sumo podría pensarse que el asegurador puede proponer, para excusarse de pago válidamente y mientras adelanta proceso para probar los perjuicios que alega, la excepción de contrato no cumplido". ${ }^{3}$

Ahora, precisado este panorama, que repetimos, consideramos difuso en cuanto a la redacción misma de la norma, podríamos realizar una lista enunciativa, nunca taxativa, que en gracia de discusión describa los que podrían ser los perjuicios sufridos en mayor o menor grado, por la aseguradora:

- Pierde el control sobre la conducta del asegurado respecto de la carga de evitar la extensión y propagación del siniestro.

- Se diluye el acceso a la información sobre las circunstancias de tiempo, modo y lugar en que ocurrió el siniestro.

- Se pierde el control oportuno y objetivo sobre la verdadera siniestralidad del asegurado.

3 Al respecto, los profesores Hugo Cárdenas Villareal, Panameño, nacionalizado en Chile, y Ricardo Reveco Urzúa, Chileno, en su obra "Remedios Contractuales", Thomson Reuters, julio 2018, traen la noción de "Excepción de contrato no cumplido", así: "Dentro de los remedios defensivos frente al incumplimiento se encuentra la denominada excepción de contrato no cumplido o, si se prefiere, de inejecución, incumplimiento recíproco o contemporáneamente, de suspensión de la prestación. Se trata de una defensa (judicial o extrajudicial) que puede hacer valer el contratante a quien se le está exigiendo el cumplimiento de una obligación, cuando su contraparte no ha cumplido o no está llana a hacerlo con su obligación correlativa. En particular, la excepción se opone cuando se produce un incumplimiento recíproco de las obligaciones que emanan de un contrato bilateral y supone, en opinión de nuestros tribunales, el reconocimiento implícito del incumplimiento de quien lo alega". 
- No se realizan mediciones de siniestralidad, en general del producto y en particular, como lo decíamos, del asegurado.

- Se incrementan los costos de los daños, y con ello la siniestralidad.

- Se incurre en la necesidad de reservar siniestros ocurridos, no avisados.

- No se realizan las reservas, generando serias desviaciones en la siniestralidad.

- Se pierden oportunidades para realizar ajustes y reservas objetivas.

- Se afecta notablemente la toma de decisiones respecto de la renovación o no del contrato al término de la vigencia, o antes si es del caso, modificación de las condiciones al momento de renovar, tales como exigencias de garantías y ajuste y modificación de primas, análisis objetivo del riesgo, entre otras.

- En suscripciones nuevas, se puede incurrir en reticencias, inexactitudes e indebida ilustración sobre el verdadero estado del riesgo.

- Se impiden o restringen las labores de salvamento, en caso de existir.

\subsection{Seguros obligatorios de responsabilidad civil en Co- lombia}

Pertinente es citar, así sea de forma enunciativa y a manera de ilustración, los productos que actualmente existen en Colombia, respeto del aseguramiento obligatorio de responsabilidad civil, pues con ello se pone de presente la importancia de la obligación de dar aviso oportuno del siniestro, en un país donde en forma exponencial crece la regulación de las diferentes formas de aseguramiento de la responsabilidad civil, seguro con un análisis económico, técnico y jurídico de los riesgos que genera la industria, la tecnología, la empresa y en general la conducta y actividad del ser humano, veamos:

\begin{tabular}{|ll|}
\hline 1. & Transporte público automotor colectivo terrestre de pasajeros \\
\hline 2. & Transporte público terrestre automotor de pasajeros \\
\hline 3. & Transporte público terrestre automotor individual de pasajeros en ve- \\
hículos taxi \\
\hline 4. & Transporte público terrestre automotor de carga \\
\hline 5. & Transporte público terrestre automotor especial \\
\hline
\end{tabular}




\begin{tabular}{|l|}
\hline 6. Transporte público terrestre automotor mixto \\
\hline 7. Parques y diversiones y otras atracciones \\
\hline 8. Transporte por cable de personas y de carga \\
\hline 9. Transporte público ferroviario \\
\hline $\begin{array}{l}\text { 10. Accidentes acuáticos para el transporte marítimo de pasajeros y/o } \\
\text { turistas }\end{array}$ \\
\hline $\begin{array}{l}\text { 11. Contaminación para el registro provisional de naves y artefactos } \\
\text { navales }\end{array}$ \\
\hline 12. Transporte Fluvial \\
\hline $\begin{array}{l}\text { 13. Transporte, almacenamiento y distribución de combustibles líquidos } \\
\text { y gases }\end{array}$ \\
\hline 14. Transportista internacional por carretera \\
\hline 15. Operador de Transporte Multimodal \\
\hline $\begin{array}{l}\text { 16. Empresas de vigilancia privada y complementarios de seguridad } \\
\text { privada }\end{array}$ \\
\hline $\begin{array}{l}\text { 17. Empresas de servicios temporales y de agencias de intermediación } \\
\text { laboral }\end{array}$ \\
\hline 18. Cumplimiento de disposiciones legales para intermediarios laborales \\
\hline 19. Propietarios de perros potencialmente peligrosos \\
\hline 20. Directores y Administradores \\
\hline 21. Centros de diagnóstico automotor \\
\hline 22. Profesional para las sociedades corredoras reaseguros \\
\hline 23. Bares y discotecas \\
\hline 24. Transporte terrestre automotor de mercancías peligrosas por carretera \\
\hline 25. Seguro obligatorio de responsabilidad civil para agencias de aduanas \\
\hline 26. Agente de carga Internacional \\
\hline 27. Seguro Ecológico \\
\hline 28. Seguro obligatorio de cumplimiento en concesiones mineras \\
\hline 29. Parques de diversiones y atracciones o dispositivos de entretenimiento \\
\hline $\begin{array}{l}\text { 30. Seguro obligatorio de estabilidad y calidad de las viviendas de interés } \\
\text { social }\end{array}$ \\
\hline 31. Garantía única de cumplimiento del contrato estatal \\
\hline 32. Seguro Previsional \\
\hline 33. Seguro obligatorio de Riesgos Profesionales \\
\hline 34. Seguro agropecuario \\
\hline
\end{tabular}




\section{ALGUNAS PROPUESTAS O EVENTUALES SOLUCIONES}

Frente a la discusión propuesta y la falta de claridad y exigibilidad de las nomas que establecen acciones de responsabilidad a favor de las aseguradoras por el incumplimiento de sus asegurados respecto del aviso de siniestro, se presentan a continuación algunas propuestas, todas seguramente objeto de dificultades o críticas, pero que de alguna manera pretenden aportar al debate y a la importancia de brindar soluciones al gremio asegurador, ante el panorama legislativo analizado en los países referidos, con excepción de la clara regulación argentina y brasilera.

\subsection{Garantía}

Una de las propuestas que se nos ocurren, acudiendo desde luego a las instituciones existentes en el derecho de las obligaciones y específicamente en el derecho de seguros en Colombia, es darle tratamiento a este deber a título de garantía, en el entendido de que la obligación, o más bien su incumplimiento tenga unas consecuencias relevantes, esto es, impacte el contrato y con ello las obligaciones a cargo de la aseguradora, tal vez asemejando la sanción a la pérdida del derecho, como en efecto se regula en el derecho Argentino, cuya norma fue citada en el acápite correspondiente de este trabajo, veamos: "Art. 47. Mora. Sanción. El asegurado pierde el derecho a ser indemnizado, en el supuesto de incumplimiento de la carga prevista en el párrafo $1^{\circ}$ del artículo 46 , salvo que acredite caso fortuito, fuerza mayor o imposibilidad de hecho sin culpa o negligencia." (Subraya fuera de texto).

Si la razón de ser del contrato de seguro es trasladar un riesgo, en este caso, el de la responsabilidad civil en que incurra el asegurado, no se entiende la razón por la cual, el asegurado no cumpla con su claro deber, por demás de simple cumplimiento, de dar aviso oportuno del siniestro, y si es tal la negligencia, desidia, desorden o desinterés, que esta conducta entonces se traduzca en la inexigibilidad de las obligaciones derivadas del amparo contratado, dicho más gráficamente, la aseguradora recibe el amparo de los eventos de responsabilidad civil en que incurra el asegurado, pero si este no le informa, como lo debe hacer en forma diligente y dentro del término establecido, u otro mayor pactado si es del caso, no tendrá la compañía porque asumir el riesgo, esto es, la aseguradora recibe el riesgo, desde luego, lo ampara, pero por lo menos informe en caso de siniestro, y además despliegue las conductas tendientes a evitar su extensión y propagación, so pena de no realizar el reconocimiento y pago, y por tanto perder su derecho a la indemnización o reembolso según el caso. 
Aterrizado lo anterior a la figura de la garantía, regulada en el derecho de los seguros en Colombia, tenemos:

\begin{abstract}
ARTÍCULO 1061. Definición de garantía. Se entenderá por garantía la promesa en virtud de la cual el asegurado se obliga a hacer o no determinada cosa, o a cumplir determinada exigencia, o mediante la cual afirma o niega la existencia de determinada situación de hecho.

La garantía deberá constar en la póliza o en los documentos accesorios a ella. Podrá expresarse en cualquier forma que indique la intención inequívoca de otorgarla.

La garantía, sea o no sustancial respecto del riesgo, deberá cumplirse estrictamente. En caso contrario, el contrato será anulable. Cuando la garantía se refiere a un hecho posterior a la celebración del contrato, el asegurador podrá darlo por terminado desde el momento de la infracción.
\end{abstract}

Dar por terminado el contrato de seguro desde el momento de la infracción, esto es, desde el momento en que el asegurado omita dar aviso del siniestro, implica claramente que no procede el reconocimiento del amparo, en virtud precisamente de la terminación del contrato. Ello puede ser drástico, pero con un comportamiento adecuado y oportuno de parte del asegurado, como lo exige la norma, no se estaría frente al riesgo de terminación del contrato y más aún, de no pago del riesgo amparado, por lo que consideramos que una posible solución al problema, que por lo menos la norma Colombiana del aviso del siniestro no resuelve, sería esta, traída, repetimos, del mismo ordenamiento jurídico del contrato de seguros, esto es, no se trata de una institución ajena al referido contrato, sino de su esencia, de su formación, de su estructura, y desde luego, debidamente regulada por el legislador, con lo cual habrá eso sí, que modificar la forma de suscripción, para incluir como clausula expresa de garantía, inequívoca, clara, pactada por escrito, como excepción a la consensualidad, esta condición.

\title{
3.2. Deducibles diferenciales
}

Otra propuesta, tal vez más novedosa, pero igual traída de una figura derecho de seguros, es la implementación de los deducibles, aplicados en forma dife- 
rencial o en escala si se quiere, para incentivar el aviso oportuno, o lo que es lo mismo desincentivar el incumplimiento de la obligación de dar avis oportuno a la aseguradora sobre el acaecimiento del siniestro. La redacción, la cual deberá constar en la póliza, no obstante la consensualidad, para evitar discusiones complejas y probatorias, sería más o menos del siguiente tenor: "Modificación de deducibles: El deducible pactado para los amparos de responsabilidad civil extracontractual y responsabilidad civil contractual en la carátula de la póliza y sus anexos, se mantendrá siempre y cuando el asegurado o tomador, informe sobre la ocurrencia del siniestro a la compañía aseguradora dentro de los 15 días calendario siguientes a la ocurrencia del mismo". Nótese que la norma colombiana habla de tres días, otras hablan de cinco, en fin, en este caso se ampliaría inclusive el plazo, lo cual es permitido en general por los ordenamientos jurídicos analizados, al ser una norma supletiva en cuanto el aplazo, en tanto permite pactar mayores plazos, pero nunca reducirlos.

Continuaría la redacción así: "En caso de presentarse el aviso del siniestro a la aseguradora, por fuera del término pactado, el deducible se modificará en las siguientes proporciones, de acuerdo al número de días transcurridos:

\begin{tabular}{|ll|}
\hline Dentro de los 15 días calendario: & 10\%, mínimo 2 SMLMV \\
\hline De 16 a 60 días calendario: & 20\%, mínimo 6 SMLMV \\
\hline De 61 a 90 días calendario: & $30 \%$, mínimo 10 SMLMV \\
\hline Más de 90 días calendario: & 50\%, mínimo 20 SMLMV \\
\hline
\end{tabular}

Se trata de dos propuestas, que seguramente habrán de estudiarse más a fondo, no sólo desde lo jurídico, son desde lo técnico, actuarial, contractual, desde el derecho de consumo, en fin, habrá de armonizar varias instituciones del derecho civil, comercial, de las obligaciones, de tal manera que, bien el tema de la garantía, de la esencia del seguro, como el deducible, igualmente del ADN del seguro, se tomen herramientas, para informarle al asegurado y que realmente tome conciencia de la importancia del aviso oportuno del siniestro, so pena de unas sanciones desde luego gravosas, que permitan a la aseguradora hacer efectiva, de alguna manera diferente a la establecida, la exigibilidad de la obligación y su correlativa sanción a título de indemnización de los perjuicios causados por dicho incumplimiento.

4 Se refiera a Salarios mínimos legales mensuales vigentes, que para el caso Colombiano 1 SMLMV en 2018, asciende a la suma de \$781.242. 


\section{BIBLIOGRAFÍA}

ÁLVAREZ PÉREZ, Andrés Orión, 2018. Los seguros obligatorios y voluntarios en los accidentes de circulación. Editorial Legis.

CÁRDENAS VILLAREAL, Hugo, 2018. Remedios Contractuales, Editorial Thomson.

JARAMILLO JARAMILLO, Carlos Ignacio, 2013. Los deberes de evitar y mitigar el daño, Funciones de la responsabilidad civil en el Siglo XXI y trascendencia de la prevención. Pontificia Universidad Javeriana y Editorial Temis.

JARAMILLO JARAMILLO. Carlos Ignacio, 2011. La configuración en el siniestro en el seguro de la responsabilidad civil. Pontificia Universidad Javeriana y Editorial Temis.

LÓPEZ BLANCO, Hernán Fabio, 2010. Comentarios al contrato de seguro. Dupré Editores, $5^{\mathrm{a}}$. edición.

ORDOÑEZ ORDOÑEZ, Andrés E., 2004. Las obligaciones y cargas de las partes en el contrato de seguro y la inoperancia del contrato de seguro. Universidad Externado de Colombia.

SAN MARTÍN NEIRA, Lilian C., 2012. La carga del perjudicado de evitar o mitigar el daño. Universidad Externado de Colombia.

STIGLITZ, Rubén S., 2010. Temas de derechos de seguros. Pontificia Universidad Javeriana. Grupo Editorial Ibáñez.

VÉLEZ OCHOA, Ricardo, 2013. La carga de evitar la extensión y propagación del siniestro. Pontificia Universidad Javeriana y Grupo Editorial Ibañez.

\section{Jurisprudencia}

Código de Comercio. Art. 1714

Código de Comercio. Art. 1715.

Ley $35 / 2015$, de septiembre 22, de reforma al sistema para la valoración de los daños y perjuicios causados a las personas en accidente de tránsito.

Ley $35 / 2015$, de septiembre 22, de reforma al sistema para la valoración de los daños y perjuicios causados a las personas en accidente de tránsito.

Proyecto de Ley 120 de 2017, Senado - Congreso de la República de Colombia, Ponente Iván Leonidas Name Vásquez.

Corte Suprema de Justicia, Sala Civil, sentencia de agosto 2 de 2001, Magistrado Ponente, Carlos Ignacio Jaramillo Jaramillo. 
Corte Suprema de Justicia, Sala Civil, sentencia de diciembre 16 de 2010, Magistrado Ponente Arturo Solarte Rodríguez, Radicado 11001-3103008-1989-00042-01. 


\section{Jurisprudencia}

Código de Comercio. Art. 1714

Código de Comercio. Art. 1715.

Ley $35 / 2015$, de septiembre 22, de reforma al sistema para la valoración de los daños y perjuicios causados a las personas en accidente de tránsito.

Ley 35/2015, de septiembre 22, de reforma al sistema para la valoración de los daños y perjuicios causados a las personas en accidente de tránsito.

Proyecto de Ley 120 de 2017, Senado - Congreso de la República de Colombia, Ponente Iván Leonidas Name Vásquez.

Corte Suprema de Justicia, Sala Civil, sentencia de agosto 2 de 2001, Magistrado Ponente, Carlos Ignacio Jaramillo Jaramillo.

Corte Suprema de Justicia, Sala Civil, sentencia de diciembre 16 de 2010, Magistrado Ponente Arturo Solarte Rodríguez, Radicado 11001-3103-008-1989-00042-01. 